$\underline{\text { Research Article }}$

\title{
STUDENTS' KNOWLEDGE AND RISK OF COMMITTING MEDICATION ERRORS IN TWO SCHOOLS OF PHARMACY IN NIGERIA
}

\author{
UBAKA CM${ }^{1}$, EKWE $C^{1}$, ISAH ${ }^{1 *}{ }^{1 *}$ MUKHTAR AB ${ }^{2}$, UKWE $^{1}{ }^{1}$ \\ ${ }^{1}$ Department of Clinical Pharmacy and Pharmacy Management, Pharmacy Practice and Pharmaceutical Care Research Group, University \\ of Nigeria, Nsukka, Enugu State, Nigeria. ${ }^{2}$ Department of Pharmaceutical Services, Kaduna State University Teaching Hospital, Barau \\ Dikko, Kaduna State, Nigeria. Email: abdulmuminu.isah@unn.edu.ng \\ Received: 02 May 2020, Revised and Accepted: 15 June 2020
}

ABSTRACT

Objective: The aim of this study was to determine the knowledge of prescription errors, the certainty of such knowledge, and the risk of committing medication errors among pharmacy students in two universities in Nigeria.

Methods: This study was a cross-sectional comparative survey between pharmacy students of two universities in Nigeria: University of Nigeria, Nsukka (UNN) and Nnamdi Azikiwe University (NAU), Awka. Study variables were measured using four simulated prescriptions and questionnaires. Chi-square test, independent t-test, and ordinal regression analyses were used to assess study outcomes.

Results: A total of 339 pharmacy students (239 in UNN and 100 in NAU), with a mean age of 24 (2.8) years and 57.2\% (n=194) male students, participated in this study. Their accurate knowledge of each of the prescriptions were 294 (86.72\%), 166 (48.97\%), 199 (58.70\%), and 248 (73.16\%) for prescriptions with error of drug allergy, error of drug interaction, no error, and wrong dose of a drug, respectively. Students from UNN were more likely to commit a statistically significant high risk of error compared to NAU students in prescriptions with a drug allergy and wrong dose, while students in the $4^{\text {th }}$ year class had a statistically significant higher odds of committing a drug interaction prescription error compared to final year students.

Conclusion: Pharmacy students evaluated in this study had good knowledge of medication error detection. The risk of these pharmacy students committing a prescription error was evident in nearly all prescriptions tested and the students' school was the major predictor of these risks.

Keywords: Drug safety, Knowledge, Medication errors, Risk of error.

(C) 2020 The Authors. Published by Innovare Academic Sciences Pvt Ltd. This is an open access article under the CC BY license (http://creativecommons. org/licenses/by/4. 0/) DOI: http://dx.doi.org/10.22159/ajpcr.2020.v13i9.38133

\section{INTRODUCTION}

Medication error is defined as "a failure in the treatment process that leads to harm to the patient" and it can occur at different stages in the provision of drugs to a patient [1-6]. Any health professional involved with drugs and patient care is vulnerable to make an error during the production, prescribing, transcribing, dispensing, and administration phase of a drug [7]. One of the six main types of medication errors that affect drug safety in patients is a prescription error which is present at the time between prescribing and transcribing, and just before dispensing $[6,8]$. Medication errors occur when the prescriber passes the wrong information to other healthcare professionals or patients [9]. From the pharmacists' perspective, it is also committed when there is inaction or inability to identify and correct a prescribing fault and/or a poor transcription of a well-written prescription just before dispensing, oftentimes referred to as dispensing error [10-13]. These errors, potential or actual, are prevalent and have consequences either by the tendency to cause serious harm to the patients or cause the patients to incur more hospital costs. In the United Kingdom (UK), the incidences of the different medication errors were reported to be $16 \%$, $18 \%$, and $50 \%$ for prescribing, dispensing, and administration errors, respectively [14]. Higher values of 3-37\%, 5-58\%, and $72-75 \%$ were reported for the same respective error types among pediatric patients in the same UK [15]. Drug-related errors cause an estimated 7000 deaths/year in the United States of America (USA) [16]. Furthermore, in the USA, it has been estimated that adverse drug events (often a consequence of drug-related errors) cost a single teaching hospital $\$ 5.6$ million, of which $\$ 2.8$ million was preventable $[17,18]$. Therefore, most medication errors can be averted if the pharmacists could identify prescription errors and not commit dispensing errors $[10,13]$.
The quality dispensing practice of the pharmacists requires that an effective form of the correct medicines is delivered to the right patient, in the correct dosage and quantity, with clear instructions, and in a package that maintains the potency of the medicine [19-22]. When the request for a drug is made through a prescription, the pharmacist is positioned to accurately interpret the wishes of the prescriber. A prescription is an order for a medicine communicated to a pharmacist by a duly licensed practitioner authorized by law to prescribe and administer such drugs or medical supplies [1,23,24]. The accurate interpretation of the prescription entails its validation. Inaccuracies in the interpretation of prescriptions do exist in prescription filling among pharmacists and constitute an error.

Some studies have shown a considerable occurrence of drug-related errors committed by younger pharmacists and it important to know if these inadequacies are also present when they are in the pharmacy schools [25-27]. The detection and correction of prescription errors have been assessed among pharmacy students in some countries [28,29], but no such study has been reported from Nigeria. Thus, the aim of this study was to determine the level of knowledge of prescription errors, the certainty of the knowledge, and the risk of committing prescription errors among pharmacy students of two public universities in Nigeria.

\section{METHODS}

This study adopted two cross-sectional surveys and was designed as a comparison between $4^{\text {th }}$ and final year students of two schools of pharmacy. The survey employed the use of four standardized simulated prescriptions and a follow-up questionnaire to elicit responses (detection of error, certainty of answer provided, and appropriate 
alternatives to be chosen in the case of an error) from the students during the 2016/2017 academic session.

This study was conducted in the schools of pharmacy at the University of Nigeria, Nsukka (UNN) and Nnamdi Azikiwe University (NAU), Awka, the two largest publicly funded universities in the South-eastern region of Nigeria. The pharmacy school at UNN commenced pharmacy training in 1967 and has produced the largest number of pharmacists in the entire country since formal training of pharmacists started in Nigeria in the early 1960s. The pharmacy school at NAU was established in 2006 as the second pharmacy school in the region.

Both pharmacy schools adopt nearly a similar curriculum and teach pharmacotherapeutics, clinical clerkship, and dispensing in the final year of study of the 5-year Bachelor of Pharmacy program. Furthermore, the introduction to clinical pharmacy concepts and pharmacy management competency training is done in the penultimate $\left(4^{\text {th }}\right.$ year $)$ year of study. A total of 631 (comprising 183 final year students and $2404^{\text {th }}$ year students in UNN; 110 final year students; and $984^{\text {th }}$ year students in NAU) pharmacy students were enrolled in the study.

The instrument used for this study was adapted from two previous studies [30,31]. The questionnaire was designed to collect participants' demographic characteristics, their knowledge of error detection, certainty of this knowledge, and the risk of committing medication errors.

It comprised four simulated prescriptions, each with additional patient information that could assist the participants in detecting the errors. A prescription error was included in each prescription (except in one prescription) and blinded to the participants. The participants were then asked if the prescription was correctly written by the prescriber. The second question sought to know the certainty of their choice in the correctness of each prescription. Thereafter, participants were asked to detect the exact prescription error (if it existed), from possible options which included drug-allergy contraindication, drug-drug interaction, wrong dosage regime, and wrong indication for drugs. Finally, a question on the best alternative drug to treat the patients' condition with options was provided for each prescription. Patient information provided in the prescriptions included name, age, weight, allergies, current medication, and diagnosis for the prescription under consideration. The prescriptions were reviewed by a senior pharmacist and an expert in pharmacotherapy and clerkship at the University of Nigeria Teaching Hospital. Below are the details of each of the four prescriptions, A to D:

- Prescription A had an error of drug-allergy contraindication. The patient's information indicated allergy for sulfonamides, yet cotrimoxazole, and amoxicillin were prescribed for her diagnosis of pneumonia

- Prescription B had an error of potential drug-drug interaction. The patient was prescribed amlodipine $5 \mathrm{mg}$ with phenobarbitone to treat a comorbid condition of essential hypertension and partial seizure

- Prescription C had no identifiable prescription error. A patient with the transient ischemic attack was prescribed warfarin and paracetamol. This prescription was included to discourage guessing by the students

- Prescription D had an error of the wrong dosage regime (an overdose). The patient had a case of uncomplicated malaria in a child weighing $10 \mathrm{~kg}$, who was prescribed artemether/lumefantrine and paracetamol.

For all prescriptions, the knowledge questions were graded as correct (1) or incorrect (0). Unanswered questions were also scored as incorrect (0). For each question, the participants indicated a selfestimated degree of certainty. The certainty for each knowledge answer provided was graded from very sure (4), sure (3), not sure (2), and need to find out (1). Risk of prescription error was defined as a combination of knowledge and certainty for each question, rated on a scale: Low (1), moderate (2), and high risk (3). A correct knowledge answer combined with high certainty (certain or very certain) was regarded as a low risk of error (score =1). Any knowledge answer combined with low certainty (not really certain or very uncertain) was regarded as a moderate risk of error (score=2). An incorrect knowledge answer combined with high certainty (certain or very certain) was regarded as a high risk of error (score=3).

\section{Data analysis}

The retrieved questionnaires were coded into Microsoft Excel 2013, from where the data were exported into IBM SPSS Version-25 for statistical analysis. Appropriate descriptive and inferential statistical analyses were conducted on the data, depending on the data distribution. Frequencies, means, and standard deviations (SD) were used to describe the participants' characteristics. The differences in those characteristics between the two schools were determined using Chi-square. The study variables (knowledge, certainty, and risk of error) were measured using means, SD, and percentages. The variables were measured based on the students' schools and based on their classes. Chi-square test was also performed to determine the differences in the distribution according to their schools and classes. The differences in their mean score were determined using an independent t-test. Ordinal regression (plum, with a dummy odds ratio of zero) was conducted to establish the students' characteristics that predicted their risk of errors (low, moderate, or high). For all analyses, 2-tailed significance tests were used, and $\mathrm{p}<0.05$ was considered statistically significant.

\section{RESULTS}

In total, 339 students participated in this study (representing an overall participation rate of $53.7 \%$ ), 239 of who were from UNN (school participation rate of 56.5\%), while 100 were from NAU (school participation rate of 48.1\%). The students' mean age was 24 $(\mathrm{SD}=2.8$ ) years, but those from UNN were younger than those from NAU $(p=0.011)$. There were more male $(n=194)$ than female students in the entire population and the gender distribution was different between the two schools ( $p=0.002)$. Majority of the students $(n=264,77.9 \%)$ had a history of filling prescriptions during their $3^{\text {rd }}$-year industrial training, and there was no difference by school $(\mathrm{p}=0.34)$. Table 1 contains a description of the participants' demographic characteristics.

Knowledge of prescription errors, certainty of knowledge, and risks of errors

The proportions of the students that had correct knowledge for the four prescriptions were 294 (86.72\%) for prescription A, 166 (48.97\%) for prescription B, 199 (58.70\%) for prescription C, and 248 (73.16\%) for

Table 1: Characteristics of study participants

\begin{tabular}{|c|c|c|c|}
\hline Variable & $\begin{array}{l}\text { University of } \\
\text { Nigeria }(n=239)\end{array}$ & $\begin{array}{l}\text { NAU } \\
(n=100)\end{array}$ & p-value \\
\hline Age, mean & $23.76(\mathrm{SD}=2.45)$ & $\begin{array}{l}24.60 \\
(\mathrm{SD}=3.33)\end{array}$ & $0.011^{*}$ \\
\hline \multicolumn{4}{|l|}{ Gender } \\
\hline Female & $90(37.7)$ & $55(55.0)$ & $0.002^{*}$ \\
\hline Male & $149(62.3)$ & $45(45.0)$ & \\
\hline \multicolumn{4}{|l|}{ Year of study } \\
\hline $4^{\text {th }}$ year & $158(66.1)$ & $38(38.0)$ & $\leq 0.0001^{*}$ \\
\hline $5^{\text {th }}$ year & $81(33.9)$ & $62(62.0)$ & \\
\hline \multicolumn{4}{|l|}{ Previous IT? } \\
\hline Yes & $219(90.6)$ & $71(71.0)$ & $\leq 0.0001^{*}$ \\
\hline No & $20(8.4)$ & $29(29.0)$ & \\
\hline \multicolumn{4}{|c|}{ Level of satisfaction with IT } \\
\hline $\begin{array}{l}\text { Very satisfied/ } \\
\text { satisfied }\end{array}$ & $133(57.3)$ & $57(79.2)$ & $\leq 0.0001^{*}$ \\
\hline $\begin{array}{l}\text { Slightly satisfied/ } \\
\text { Not at all satisfied }\end{array}$ & $99(42.7)$ & $15(20.8)$ & \\
\hline \multicolumn{4}{|c|}{ Prescriptions fill history? } \\
\hline Yes & $188(78.7)$ & $76(76.0)$ & 0.34 \\
\hline No & $51(21.3)$ & $24(24.0)$ & \\
\hline
\end{tabular}


prescription D. There was no significant difference in the proportion of correct knowledge answers provided for prescription A between students of both schools. Students from UNN had a statistically significant lower certainty assessment and a higher risk of committing an error with the prescription having a drug allergy contraindication $(p<0.05$ for both). There was no significant difference between responses from pharmacy students from the schools in knowledge, certainty evaluation, or risk of error for the prescription with a drug interaction (B). For the prescription with no error (C), students from UNN expressed better knowledge and much lower risk of errors $(p<0.05)$. For the prescription with a wrong dose, students from NAU showed significantly higher knowledge, lower level of certainty, and hence lower risk of prescription error (Table 2).

Regarding students' responses by year of study, $5^{\text {th }}$-year students expressed better knowledge and lower risk of committing a prescription error than $4^{\text {th }}$-year students in only the prescription with a drug interaction (Table 3).

The proportion of students with a high risk of prescription error was higher in UNN for prescriptions 1, 3, and 4, all having a statistically significant difference (Table 4).
Table 5 shows pharmacy students' knowledge of appropriate alternatives for any of the errors identified by schools and study years. In prescription B (with error of drug-drug interaction), more pharmacy students from UNN had better knowledge of the appropriate alternative $(\mathrm{p}<0.0001)$, while students from NAU had more knowledge for appropriate alternative in prescription $\mathrm{D}$, with a wrong dosage regimen $(p=0.007)$. Knowledge of appropriate alternatives in all cases of prescription errors was similar among students of both $4^{\text {th }}$ year and $5^{\text {th }}$ year of study.

Ordinal regression analysis showed students from UNN were more likely to commit a high risk of error with prescriptions with the drugallergy contraindication (odds ratio $[\mathrm{OR}]=0.777$; 95\% confidence interval [CI]: 0.063-1.492; Wald $\mathrm{X}^{2}(1)=4.545, \mathrm{p}=0.033$ ) and wrong dose (OR=0.783; 95\% CI: 0.0.181-1.384; Wald $\mathrm{X}^{2}(1)=6.508, \mathrm{p}=0.011$ ) compared to NAU students. In contrast, pharmacy students from UNN were less likely to commit a high-risk error (OR=-0.720; 95\% CI: $-1.218-$ -0.222 ; Wald $\mathrm{X}^{2}(1)=8.038, \mathrm{p}=0.005$ ) in the prescription with no error at all in it. For the prescription with an error of drug-drug interaction, students in $4^{\text {th }}$-year class irrespective of school were $60 \%$ more likely to commit higher risks of error compared to $(\mathrm{OR}=0.633$; $95 \% \mathrm{CI}$ : $0.192-$ 1.075; Wald $X^{2}(1)=7.903, p=0.005$ ) students in the final year (Table 6).

Table 2: Prescription knowledge, certainty evaluation, and risk of prescription error by each school of pharmacy

\begin{tabular}{|c|c|c|c|c|c|c|}
\hline \multirow[t]{2}{*}{ Prescriptions } & \multicolumn{2}{|c|}{$\begin{array}{l}\text { Proportion (\%) of correct } \\
\text { knowledge answers }\end{array}$} & \multicolumn{2}{|c|}{$\begin{array}{l}\text { Certainty in each knowledge } \\
\text { answer (1-4), (SD) }\end{array}$} & \multicolumn{2}{|c|}{$\begin{array}{l}\text { Risk of prescription error } \\
\text { score (1-3), (SD) }\end{array}$} \\
\hline & UNN & NAU & UNN & NAU & UNN & NAU \\
\hline Prescription 1 (drug-allergy contraindication) & $203(84.9)$ & $91(91.0)$ & $3.31(0.87)$ & $3.56(0.70)$ & $1.36(0.67)$ & $1.19(0.52)$ \\
\hline Prescription 2 (drug-drug interaction) & $115(48.1)$ & $51(51.0)$ & $2.90(0.96)$ & $3.08(0.87)$ & $2.03(0.83)$ & $1.96(0.86)$ \\
\hline Prescription 3 (well written prescription) & $152(63.6)$ & $47(47.0)$ & $2.94(0.84)$ & $3.09(0.88)$ & $1.76(0.89)$ & $2.08(0.87)$ \\
\hline Prescription 4 (wrong dose regimen) & $167(69.9)$ & $81(81.0)$ & $3.36(0.77)$ & $3.67(0.63)$ & $1.61(0.86)$ & $1.39(0.78)$ \\
\hline
\end{tabular}

${ }^{*} \mathrm{p}<0.05$. UNN: University of Nigeria, Nsukka, NAU: Nnamdi Azikiwe University

Table 3: Prescription knowledge, certainty evaluation, and risk of prescription error for each study year

\begin{tabular}{|c|c|c|c|c|c|c|}
\hline \multirow[t]{2}{*}{ Prescriptions } & \multicolumn{2}{|c|}{$\begin{array}{l}\text { Proportion (\%) of correct } \\
\text { knowledge answers }\end{array}$} & \multicolumn{2}{|c|}{$\begin{array}{l}\text { Certainty in each knowledge } \\
\text { answer (1-4), (SD) }\end{array}$} & \multicolumn{2}{|c|}{$\begin{array}{l}\text { Risk of prescription error } \\
\text { score }(1-3),(S D)\end{array}$} \\
\hline & $5^{\text {th }}$ year & $4^{\text {th }}$ year & $5^{\text {th }}$ year & $4^{\text {th }}$ year & $5^{\text {th }}$ year & $4^{\text {th }}$ year \\
\hline Prescription 1 (drug-allergy contraindication) & $127(88.8)$ & $167(85.2)$ & $3.53(0.72)^{*}$ & $3.28(0.88)^{*}$ & $1.27(0.61)$ & $1.35(0.65)$ \\
\hline Prescription 2 (drug-drug interaction) & $80(55.9)^{*}$ & $86(43.9)^{*}$ & $2.97(0.95)$ & $2.94(0.93)$ & $1.85(0.85)^{*}$ & $2.13(0.82)^{*}$ \\
\hline Prescription 3 (well written prescription) & $82(57.3)$ & $117(59.7)$ & $3.02(0.82)$ & $2.95(0.88)$ & $1.92(0.87)$ & $1.80(0.84)$ \\
\hline Prescription 4 (wrong dose regimen) & $108(75.5)$ & $140(71.4)$ & $3.46(0.78)$ & $3.45(0.72)$ & $1.52(0.82)$ & $1.56(0.85)$ \\
\hline
\end{tabular}

$* \mathrm{p}<0.05$

Table 4: Distribution of high risk of prescription error by school and study year

\begin{tabular}{|c|c|c|c|c|c|c|}
\hline \multirow[t]{2}{*}{ Prescriptions } & \multicolumn{6}{|c|}{ Proportion of students with high risk of prescription error (\%) } \\
\hline & UNN (n=239) & NAU $(n=100)$ & $\mathbf{p}$ & $5^{\text {th }}$ year $(n=143)$ & $4^{\text {th }}$ year $(n=196)$ & $\mathbf{p}$ \\
\hline Prescription 1 (drug-allergy interaction) & 10.5 & 6.0 & $0.025^{*}$ & 8.4 & 9.7 & 0.368 \\
\hline Prescription 2 (drug-drug interaction) & 36.4 & 35.0 & 0.587 & 29.4 & 40.8 & $0.006^{*}$ \\
\hline Prescription 3 (well written prescription) & 25.1 & 42.0 & $0.005^{*}$ & 34.3 & 27.0 & 0.357 \\
\hline Prescription 4 (wrong dose regimen) & 24.7 & 18.0 & $0.010^{*}$ & 21.0 & 24.0 & 0.742 \\
\hline
\end{tabular}

${ }^{*} \mathrm{p}<0.05$. UNN: University of Nigeria, Nsukka, NAU: Nnamdi Azikiwe University

Table 5: Pharmacy students' knowledge of appropriate alternative for diagnosis

\begin{tabular}{|c|c|c|c|c|c|c|}
\hline \multirow[t]{2}{*}{ Prescriptions } & \multicolumn{6}{|c|}{ Proportion of students with appropriate alternative for diagnosis (\%) } \\
\hline & UNN (n=239) & NAU $(n=100)$ & $\mathbf{p}$ & $5^{\text {th }}$ year $(n=143)$ & $4^{\text {th }}$ year $(n=196)$ & $\mathbf{p}$ \\
\hline Prescription 1 (drug-allergy interaction) & 73.6 & 82.0 & 0.064 & 77.6 & 75.0 & 0.335 \\
\hline Prescription 2 (drug-drug interaction) & 27.7 & 10.0 & $\leq 0.0001^{*}$ & 25.2 & 20.5 & 0.189 \\
\hline Prescription 3 (well written prescription) & 55.2 & 50.0 & 0.223 & 58.0 & 50.5 & 0.103 \\
\hline Prescription 4 (wrong dose regimen) & 42.7 & 58.0 & $0.007^{*}$ & 49.0 & 45.9 & 0.329 \\
\hline
\end{tabular}

$* \mathrm{p}<0.05$. UNN: University of Nigeria, Nsukka, NAU: Nnamdi Azikiwe University 
Table 6: Ordinal regression analysis between students' characteristics and risks of error

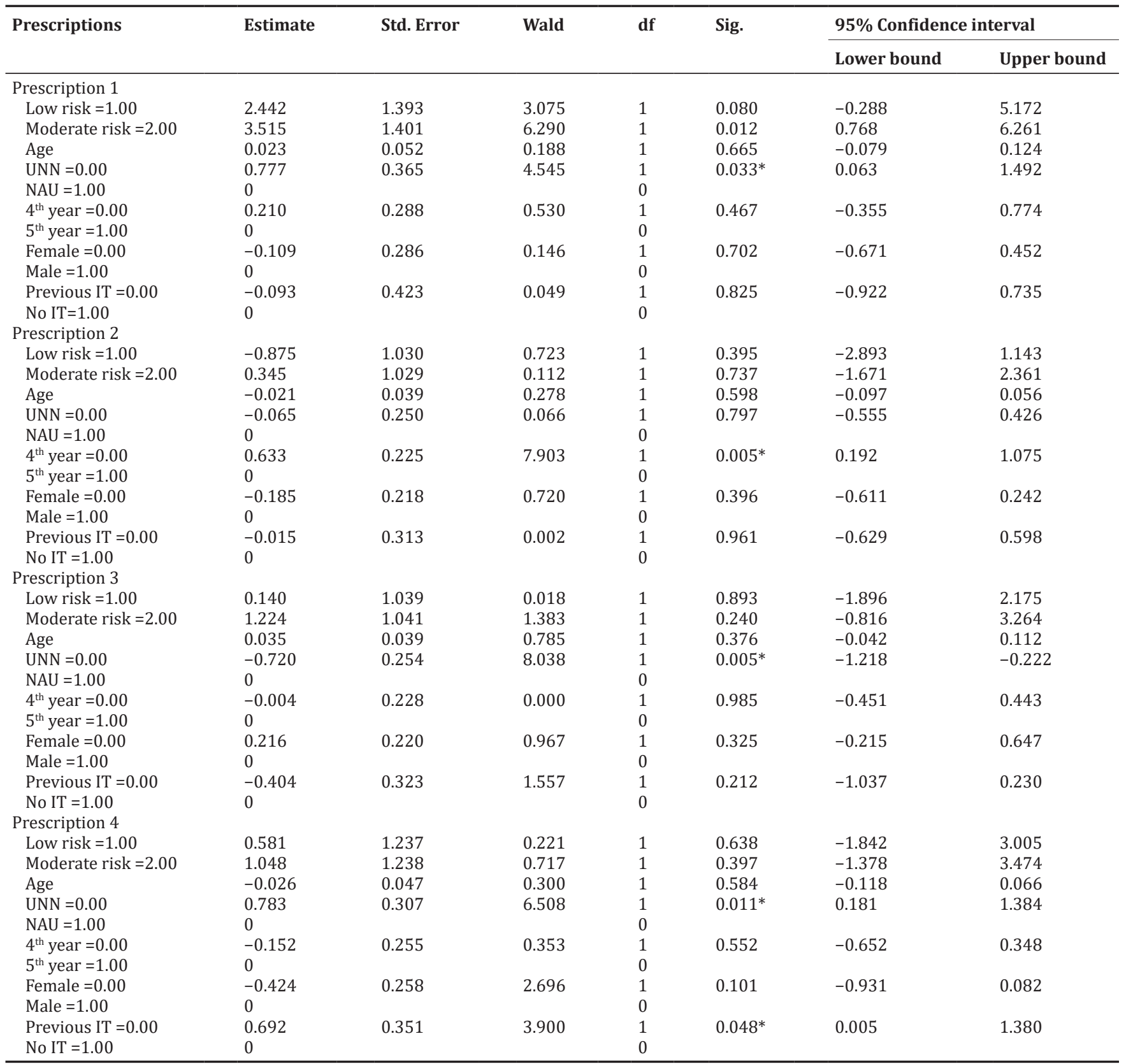

${ }^{*} \mathrm{p}<0.05$. UNN: University of Nigeria, Nsukka, NAU: Nnamdi Azikiwe University

\section{DISCUSSION}

More than half of the pharmacy students surveyed in both schools correctly detected an error in each of the prescriptions with the order of greater detection efficiency being in the prescriptions with the drug allergy contraindication, wrong dose, and drug-drug interaction. Students from UNN were more accurate in detecting the prescription with no error whereas students from NAU were more efficient in detecting the errors in the prescription with a wrong dose. Final year students were only more accurate in detecting errors in the prescription with drug interaction. The likelihood of committing a high risk of prescription error among pharmacy students from UNN was higher in the prescriptions with a drug allergy contra-indication and a wrong dose. Fourth-year pharmacy students were likely to commit an error with the prescription with a drug-drug interaction. The students' knowledge in appropriate alternatives for the prescriptions with errors showed different trends for both schools.
There are relatively few studies on prescription error knowledge and detection among pharmacists, let alone among pharmacy students. Warholak et al. study conducted among pharmacy, medical and nursing students in a university measured the ability of these students to correctly identify prescribing errors in three simulated prescriptions [31]. As with the findings of this present study, pharmacy students in the comparative study produced a high knowledge of the detection of prescription errors in most of the prescriptions used. A very similar knowledge level of prescription error in this study was observed in the prescription with a wrong drug dose in the comparative study with other health professional students. The authors think that better knowledge of prescription errors can be attributed to the greater and consistent focus of pharmacy school curricula on medications, their actions, and rational use. Facchinetti et al. study focused on the comparative knowledge of prescription errors among pharmacists and licensed nurses and found the latter to possess significantly better knowledge most, especially in errors of wrong doses [32]. 
It is also worthy of note that the prescription with a drug-drug interaction proved to be the most difficult for pharmacy students to decipher, and educators are encouraged to pay close attention to that prevalent aspect of drug therapy problems. In both schools, credits on drug interactions could be increased and more emphasis on it should be explored during clerkship rounds. The use of technological aids and software (e.g., Medscape ${ }^{\circledR}$, Lexi-interact ${ }^{\circledR}$, etc.) can also be encouraged to give students a quick reference guide to identifying potential drug interaction in prescriptions. Some other studies focused on pharmacy students' knowledge of conducting medication management reviews after a comprehensive lecture [33] and pharmacy students' knowledge in comparison with medical students on pharmacology and pharmacotherapeutics [28]. Both studies reported pharmacy students' comparatively higher knowledge in the areas studied.

Regarding the better knowledge in the prescription with a wrong dose among pharmacy students from NAU, a feasible reason could stem from the school's better organized and mandatory Introductory Pharmacy Practice Experience that is undertaken between the $3^{\text {rd }}$ and $4^{\text {th }}$ years of school in NAU. Unexpectedly though, final year pharmacy students possessed better error detection knowledge in only one prescription error; drug-drug interaction. We think that the recent completion of the industrial training experience by the $4^{\text {th }}$ year students might have played a role and that the final year curriculum did not sufficiently add more knowledge into prescription error detection. We also think that the similarity in students from both classes might have been due to lack of knowledge in prescription error detection or experiential skills to detect prescription errors with little patient information. There are now calls on policymakers in Nigeria to implement the Doctor of Pharmacy program in Nigeria which not only increases the depth of content of pharmacotherapy but also the duration and skills in clinical competencies.

No study has considered the effect of year of study on the knowledge of prescription errors, but Simonsen et al. study on nurses showed practicing nurses possessing better knowledge of medication dose error than student nurses in their final year of study [30]. Pharmacy students from UNN were more likely to commit prescription errors due to their relatively poorer knowledge and especially uncertainty in their choices. More students from NAU were not certain of their choices of the presence of errors and did not select the option to seek assistance from a superior person, thus creating the room for moderate to high risk to committing an error. This calls for a need to train pharmacy students to be better critics in addressing prescription errors, especially forcing an error when it did not exist and not seeking for expert advice. This could lead to a confrontation with prescribers and further dampen interprofessional collaboration. It is expected that while assertiveness is a virtue to be encouraged among young pharmacists, the act of humility and professionalism to seek information when not certain of a clinical decision should be emphasized before and during clerkships. Pharmacy students should be trained on the benefits of teamwork and information seeking, so as to properly verify any information they have before issuing advice (a note of error on a prescription). Fourth-year students were more likely to commit the medication error with the prescription with a drug-drug interaction due to their poorer knowledge of the error compared to their senior counterparts. We think the depth of the curriculum and the clerkship course for the final years might have played a role in the lower risk potential.

Medication review and reconciliation are considered the most important solution to a medication error. The most successful interventions are medication reviews conducted primarily by pharmacists with a multicomponent focus [2], even in the community practice setting [34]. This is very important in ensuring safer health services, as $1-10 \%$ of medication errors identified in patient care are associated with patient harm [4]. There are different scales in assessing causality in adverse drug reactions, such that when that is introduced in the curriculum, the students may be better positioned to identify the adverse drug reactions errors [35].

\section{Limitations of the study}

This study was conducted in only two schools of pharmacy in South-eastern Nigeria and its results are not representative of the region. The simulated prescriptions represent three of the most common prescriptions at the University of Nigeria Teaching Hospital which generates the largest prescriptions in the region. The knowledge and risk of error by non-responders in this study could have been different from those surveyed and might have produced a result that is different from the one highlighted in this study.

The continuous evaluation of medication errors among pharmacy students in their last years in school with a view to implementing a curricular modification to increase their knowledge and reduce the potential risk of committing a medication error will be the focus of future research.

\section{CONCLUSION}

Nigerian pharmacy students evaluated in this study had good knowledge of prescription error detection. Their knowledge of drug-allergy interaction and wrong dosage regimen was excellent. The students also showed potentials of the high risk of committing medication errors in one of the prescriptions evaluated and this was influenced by their schools and years of study. Focus on identification of medication errors should be made mandatory from the $4^{\text {th }}$ year of study through the $5^{\text {th }}$ year.

\section{ACKNOWLEDGMENT}

The authors acknowledge the pharmacy students (2016/2017 academic session) of the two schools (UNN and NAU, Awka) who voluntarily participated in the study. The managements of both schools who provided the approval for conducting the study at the settings are also appreciated.

\section{AUTHORS' CONTRIBUTIONS}

Chukwuemeka M. Ubaka and Chukwubuike Ekwe participated in the conception and acquisition of data in this study. Chukwuemeka M. Ubaka and Abdulmuminu Isah conducted the data analysis. Abdulmuminu Isah, Amina B. Mukhtar, and Chinwe V. Ukwe drafted the manuscript for publication. All the authors revised the manuscript and gave the final approval for its submission.

\section{AUTHORS' FUNDING}

No specific funding was received for this study. All aspects of the study were privately funded by the authors.

\section{CONFLICTS OF INTEREST}

All the authors of this study declare that they have no conflicts of interest related to the study to declare.

\section{REFERENCES}

1. Furlan AD, MacDougall P, Pellerin D, Shaw K, Spitzig D, Wilson G, et al. Overview of four prescription monitoring/review programs in Canada. Pain Res Manag 2014;19:102-6.

2. Cohen MR. Medication errors. Nursing 2014;44:72

3. Roy V, Gupta P, Srivastava S. Medication errors: Causes and prevention. Health Adm 2006;19:60-4

4. Brunetti L, Suh DC. Medication Errors: Scope and prevention strategies. J Hosp Adm 2012;1:1-10.

5. Yu KH, Nation RL, Dooley MJ. Multiplicity of medication safety terms, definitions and functional meanings: When is enough enough? Qual Saf Health Care 2005; 14:358-63.

6. Ferner RE, Aronson JK. Clarification of terminology in medication errors: Definitions and classification. Drug Saf 2006;29:1011-22.

7. Aronson JK. Medication errors: Definitions and classification. Br J Clin Pharmacol 2009;67:599-604.

8. Ajemigbitse AA, Omole MK, Erhun WO. Medication prescribing errors in a tertiary hospital in Nigeria: Types, prevalence and clinical 
significance. West Afr J Pharm 2013;24:4857.

9. Dean B, Barber N, Schachter M. What is a prescribing error? Qual Health Care 2000;9:232-7.

10. Silva MD, Rosa MB, Franklin BD, Reis AM, Anchieta LM, Mota JA. Concomitant prescribing and dispensing errors at a Brazilian hospital: A descriptive study. Clin (Sao Paulo) 2011;66:1691-7.

11. Flynn EA, Kenneth NB, Berger BA, Lloyd KB, Brackett PD. Dispensing errors and counseling quality in 100 pharmacies. J Am Pharm Assoc 2009;49:171-82.

12. Cheung KC, Bouvy ML, De Smet PA. Medication errors: The importance of safe dispensing. Br J Clin Pharmacol 2009;67:676-80.

13. Rolland P. Occurrence of dispensing errors and efforts to reduce medication errors at the central Arkansas Veteran's healthcare system. Drug Saf 2004;27:271-82.

14. Abdel-Latif MM. Knowledge of healthcare professionals about medication errors in hospitals. J Basic Clin Pharm 2016;7:87-92.

15. Paediatric Nursing Associations of Europe. Paediatric and Neonatal Medication Errors A Position Statement by the Paediatric Nursing Associations of Europe; 2012. Available from: Available from: https://www. kinderverpleegkunde.venvn.nl/Portals/12/Policy Statement medication errors final_March 2012.pdf. [Last accessed on 2017 Dec 23].

16. Institute of Medicine. Committee on Quality of Health Care in America. To Err is Human. To Err is Human: Building a Safer Health System. United States: National Academies Press; 2000

17. Leendertse AJ, Van Den Bemt PM, Poolman JB, Stoker LJ, Egberts AC, Postma MJ. Preventable hospital admissions related to medication (HARM): Cost analysis of the HARM study. Value Heath 2011;14:34-40.

18. Bates DW, Spell N, Cullen DJ, Burdick E, Laird N, Petersen LA, et al. The costs of adverse drug events in hospitalized patients. Adverse Drug Events Prevention Study Group. JAMA 1997;277:307-11.

19. Ladak SS, Chan VW, Easty T, Chagpar A. Right medication, right dose, right patient, right time, and right route: How do we select the right patient-controlled analgesia (PCA) device? Pain Manag Nurs 2007;8:140-5.

20. American Pharmacists Association. Pharmacists' Impact on Patient Safety; 2018. Available from: http://www.pharmacist.com/sites/default/ files/PharmacistsImpactonPatientSafety Web.pdf. [Last accessed on 2017 Dec 22]

21. Cavell G. Expert pharmacist roles are needed to champion medication safety. Pharm J 2009;1:330. Available from: https:// www.pharmaceutical-journal.com/careers-and-jobs/career-feature/ expert-pharmacist-roles-are-needed-to-champion-medicationsafety/10971128. [Last accessed on 2017 Dec 22].

22. Shah A. Pharmacy Intervention in the Medication-Use Process: The Role of Pharmacists in Improving Patient Safety. Den Haag;
2009. Available from: https://www.fip.org/files/fip/patient safety/ patientsafetyadvidshah.pdf. [Last accessed on 2017 Dec 22].

23. Merriam-Webster Dictionary. Prescription Definition of Prescription by Merriam-Webster; 2015. Available from: https://www.merriamwebster.com/dictionary/prescription. [Last accessd on 2017 Dec 23]

24. US Food and Drug Administration. Questions and Answers Prescription Drugs and Over-the-Counter (OTC) Drugs: Questions and Answers. Center for Drug Evaluation and Research; 2017. Available from: https:// www.fda.gov/drugs/resourcesforyou/consumers/questionsanswers/ ucm100101htm. [Last accessed on 2017 Dec 23].

25. The Academy of Managed Care Pharmacy. Medication Errors. Vol. 1. Alexandria, Virginia: Academy of Managed Care Pharmacy; 2010. p. $1-9$

26. Schafheutle EI, Seston EM, Hassell K. Factors influencing pharmacist performance: A review of the peer-reviewed literature. Health Policy 2011;102:178-92.

27. Al-Rukban MO, Rizvi MR. Pharmacists knowledge, attitude and practices towards written prescription in dispensing and substitution of drugs in Riyadh. Majmaah J Health Sci 2014;2:28-34

28. Keijsers CJ, Brouwers JR, de Wildt DJ, Custers EJ, Ten Cate OT, Hazen AC, et al. A comparison of medical and pharmacy students' knowledge and skills of pharmacology and pharmacotherapy. Br J Clin Pharmacol 2014;78:781-8.

29. Slaughter RL, Erickson SR, Thomson PA. Clinical interventions provided by doctor of pharmacy students. Ann Pharmacother 1994;28:665-70.

30. Simonsen BO, Daehlin GK, Johansson I, Farup PG. Differences in medication knowledge and risk of errors between graduating nursing students and working registered nurses: Comparative study. BMC Health Serv Res 2014;14:1-11.

31. Warholak TL, Queiruga C, Roush R, Phan H. Medication error identification rates by pharmacy, medical, and nursing students. Am J Pharm Educ 2011;75:1-6.

32. Facchinetti NJ, Campbell GM, Jones DP. Evaluating dispensing error detection rates in a hospital pharmacy. Med Care 1999;37:39-43.

33. Basheti IA, Qunaibi EA, AbuRuz S, Samara S, Bulatova NR. Home medication reviews in a patient care experience for undergraduate pharmacy students. Am J Pharm Educ 2013;77:173

34. Abubakar U. Practices and perception of nigerian community pharmacists towards antimicrobial stewardship program. Int J Pharm Pharm Sci 2020;12:37-42.

35. Kumar AP, Bhoopathi D, Sunkara H, Chalasani SH. An overview of various scales used in causality assessment of adverse drug reactions. Int J Pharm Pharm Sci 2020;12:1-5. 